\title{
Road Networks Winter Risk Estimation Using On-Board Uncooled Infrared Camera for Surface Temperature Measurements over Two Lanes
}

\author{
M. Marchetti, ${ }^{1}$ M. Moutton, ${ }^{1}$ S. Ludwig, ${ }^{1}$ L. Ibos, ${ }^{2}$ V. Feuillet, ${ }^{2}$ and J. Dumoulin ${ }^{3}$ \\ ${ }^{1}$ CETE de l'Est-ERA 31, 71 rue de la Grande Haie, Tomblaine 54510, Nancy, France \\ ${ }^{2}$ CERTES, Université Paris-Est, 61 avenue du Général de Gaulle, 94010 Créteil Cedex, France \\ ${ }^{3}$ IFSTTAR, Université Nantes Angers Le Mans, Route de Bouaye, CS4, 44344 Bouguenais Cedex, France
}

Correspondence should be addressed to M. Marchetti, mario.marchetti@developpement-durable.gouv.fr

Received 18 February 2011; Revised 17 May 2011; Accepted 18 May 2011

Academic Editor: Nicola Masini

Copyright (c) 2011 M. Marchetti et al. This is an open access article distributed under the Creative Commons Attribution License, which permits unrestricted use, distribution, and reproduction in any medium, provided the original work is properly cited.

\begin{abstract}
Thermal mapping has been implemented since the late eighties to establish the susceptibility of road networks to ice occurrence with measurements from a radiometer and some atmospheric parameters. They are usually done before dawn during wintertime when the road energy is dissipated. The objective of this study was to establish if an infrared camera could improve the determination of ice road susceptibility, to build a new winter risk index, to improve the measurements rate, and to analyze its consistency with seasons and infrastructures environment. Data analysis obtained from the conventional approved radiometer sensing technique and the infrared camera has shown great similarities. A comparison was made with promising perspectives. The measurement rate to analyse a given road network could be increased by a factor two.
\end{abstract}

\section{Introduction}

Thermal mapping, invented in the seventies, has been implemented since the late eighties to measure road pavement temperature along with some other atmospheric parameters to establish the susceptibility of road network to ice occurrence [1-11]. Measurements are mainly done using a vehicle circulating on the road network in given road weather conditions (clear weather, cloudy, wet pavement, etc.), though the dry pavement is the most common situation. These measurements are both used for the determination of a winter risk based on the comparison of road surface temperature with dew point over the road network, and as an input for road weather forecast models based on energy balance. If the dew point temperature is below road surface temperature there is a risk of ice occurrence and therefore a loss of grip for circulating vehicles. Some numerical models could be an alternative to determine pavement temperature [12-15] at a local scale, though some measurements will still be necessary to check the relevance and the consistency of these numerical tools.
Road surface temperature is mainly obtained with an infrared radiometer providing measurements at a given spatial frequency whatever the speed of the vehicle was due to its insertion in traffic flow. The device is either installed outside or inside the vehicle. To avoid too much influence of the sun, and to see the thermal behavior of the pavement enhanced, thermal mapping is usually done before dawn during wintertime, that is when the energy accumulated by the road during daytime is mainly dissipated (by radiation, by conduction, and by convection) and before the road structure starts a new cycle. The length of a road network ranges between a few hundred of kilometres and up to several thousands kilometres when it comes to multiple lanes highways and an analysis in the two directions of a road.

This analysis is mainly done when a new road network is built, when some major pavement changes are made, or when modifications in the road surroundings took place that might affect the thermal heat balance. This helps road managers to install sensors to monitor road status on specific locations identified as dangerous, or simply to install specific road signs. A set of road events are collected by the operator 


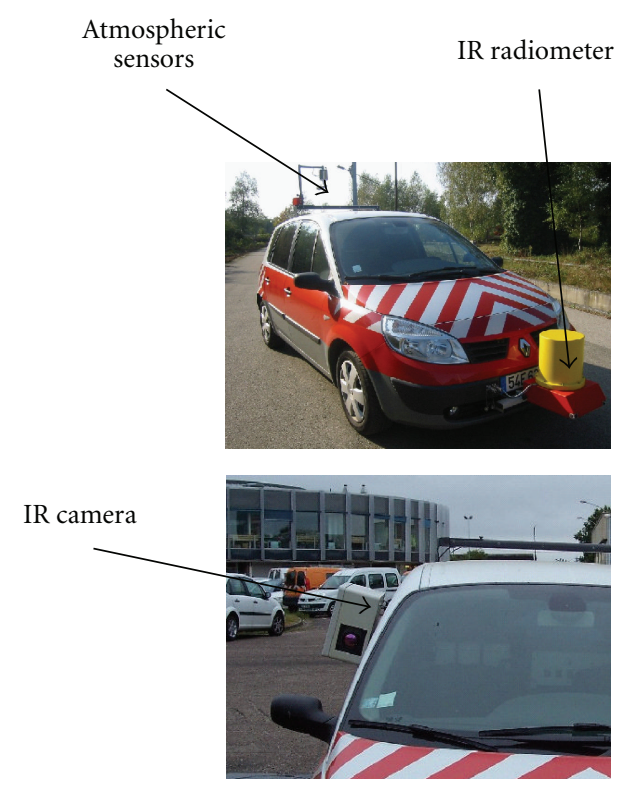

(a)

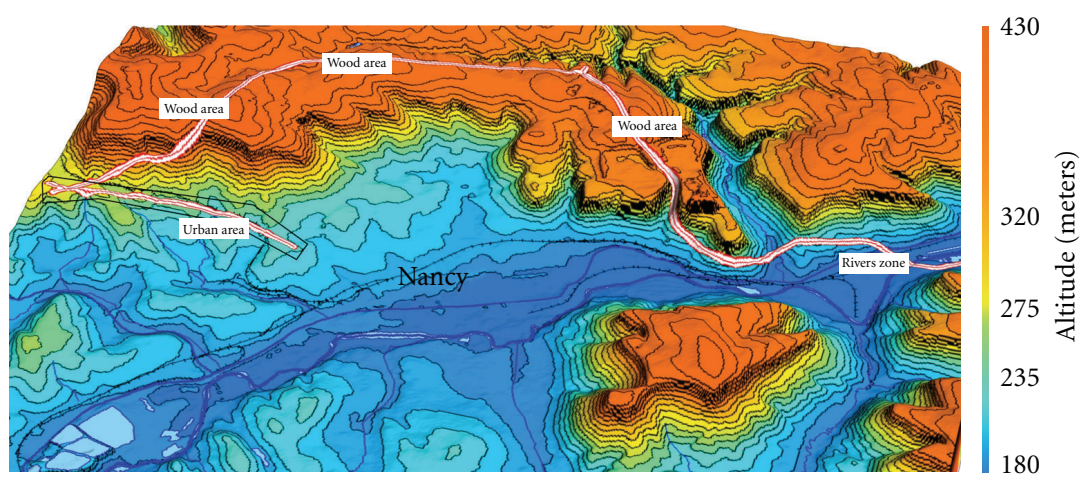

(b)

FIgURE 1: Vehicle for thermal mapping (a); map of the road network investigated (from $180 \mathrm{~m}$ (blue) to $430 \mathrm{~m}$ (red) (b).

(presence of bridges, urban areas, woods on road sides, pavement nature changes, etc.) that might help in the analysis of road thermal response.

Measurements are run at speeds allowed on the road networks, and in our case the maximum speed was $70 \mathrm{~km} / \mathrm{h}$. They are anyhow time consuming. Indeed, a whole road network can hardly be analysed at once and has to be partitioned in stretches that could be done in the open time window to avoid temperature artefacts due to a rising sun.

The LRPC Nancy has been using a vehicle for thermal mapping early after the technique appeared. The vehicle is illustrated on Figure 1. Although the whole device has great performances, such radiometer could only analyse one lane at a time. Furthermore, measurements being run before dawn, all road events are usually obtained making measurements during daytime. The road surface temperature obtained is then used to establish a rough cooling speed, aspect not detailed in this work. A map of the road network investigated is also presented in Figure 1 in order to localize urban zones, woods, rivers, some bridges, and so forth, and the type of road (highways, roads, and urban streets).

The objective of this work was to establish if the implementation of an infrared camera on a thermal mapping vehicle could improve the determination of road network susceptibility to ice occurrence. The device would provide the same information as conventional thermal mapping with a radiometer. The field of the camera will embrace several lanes, improving the measurement rate. Such camera could ease the detection and the quantification of transverse thermal gradients between lanes or within a lane. The thermal image would allow analysing the relevance of local specific winter risk. It will allow obtaining information on local thermal behavior of the road surroundings. Some difficulties have to be faced with an infrared camera, such
TABLE 1: Characteristics of PRT5 radiometer.

\begin{tabular}{lc}
\hline $\begin{array}{l}\text { Detector type } \\
\text { Spectral }\end{array}$ & Bolometer detector \\
bandwidth & $9.5-11.5 \mu \mathrm{m}$ \\
Thermal range & $-40^{\circ} \mathrm{C}$ to $+70^{\circ} \mathrm{C}$ \\
Sensitivity & $0.1^{\circ} \mathrm{C}$ below $0^{\circ} \mathrm{C}, 0.05^{\circ} \mathrm{C}$ above $0^{\circ} \mathrm{C}$ \\
Accuracy & $\pm 0.5^{\circ} \mathrm{C}$ \\
FOV & $20^{\circ}$ \\
Time response & $50 \mathrm{~ms}$ \\
NET & $0.005^{\circ} \mathrm{C}$ for a time response of $50 \mathrm{~ms}$ on a body \\
& at $25^{\circ} \mathrm{C}$ \\
\hline
\end{tabular}

as a proper focus over the whole image, the choice of emissivity value of road pavements, though also present with radiometers, the presence of thermal signatures of passing vehicles, and the data volume. The analysis of road surface temperature obtained from the radiometer and the infrared camera has shown great similarities. Comparison was made on an area located between the wheel tracks. Promising perspectives appeared to increase by a factor two the measurement rate to analyse a given road network.

\section{Description of the Experimental Devices}

2.1. Infrared Radiometer PRT5 and Atmospheric Parameters. The infrared radiometer is a PRT5 from Barnes pyrometer, with a $20^{\circ} \mathrm{FOV}$. It was mounted on the front bumper of a car, in a compartment whose temperature is regulated around $18^{\circ} \mathrm{C}$. The compartment is located at about $40 \mathrm{~cm}$ above the road surface. The characteristics of the radiometer are given in Table 1. In our study, and because of its sensitivity, 
TABLE 2: Characteristics of FLIR S65 camera.

\begin{tabular}{lc}
\hline $\begin{array}{l}\text { Detector type } \\
\text { Spectral }\end{array}$ & $\begin{array}{c}\text { Microbolometer detector uncooled IRFPA of } \\
\text { bandwidth } \\
\text { Thermal range } \\
\text { used }\end{array}$ \\
$\begin{array}{l}\text { Sensitivity } \\
\text { (NETD) }\end{array}$ & $-4.5-13 \mu \mathrm{m}$ \\
Accuracy & $0.08^{\circ} \mathrm{C}$ to $+120^{\circ} \mathrm{C}$ \\
$\begin{array}{l}\text { FOV } \\
\text { IFOV }\end{array}$ & $\pm 2 \%$ of the measurement \\
$\begin{array}{l}\text { Image acquisition } \\
\text { frequency }\end{array}$ & 1.3 mrad \\
Video output & $\mathrm{Max} 1.6 \mathrm{~Hz}($ see text for details $)$ \\
\hline
\end{tabular}

its accuracy, and its NET, this radiometer was chosen as a reference for data analysis.

During the measurements, usual atmospheric parameters such as air temperature, relative humidity, and atmospheric pressure were monitored. Measurements were provided by a SSBC probe designed to be installed on moving vehicles, including aircrafts wings [16].

\subsection{Infrared Camera FLIR S65 and Thermal Images. A FLIR} S65 camera was used. This camera has an uncooled $320 \times 240$ FPA detector in band III. The camera was installed in a compartment attached to a window on the right side of the vehicle. It was plugged to a computer through an IEEE1394 firewire interface. The camera was turned on at least 30 minutes before starting the measurements to make sure the whole electronic system has reached a thermal equilibrium. The characteristics of the camera are summarized in Table 2 .

The camera field of view (FOV) was such that each thermal image would embrace several elements of the scene, from the road pavement and up to the sky. In such configuration, the road is analyzed at a near grazing angle. A diffusive mirror was installed in the FOV of the camera, along with a surface painted with Nextel 811-21, whose emissivity is considered as stable and equal to 0.97 [17]. The Nextel paint could be used for a temperature reference if necessary. Emissivity of the mirror has been determined to 0.063 [18]. The mirror was used for environment radiative corrections. Its position in the FOV of the camera induces a blurring of the edges of the mirror. This mirror was large enough to consider that pixels in the middle could be used for these radiative corrections.

Due to the grazing angle, the measurement area for the infrared camera was located ahead of the radiometer one. There is so a distance offset between the temperature measurements obtained from the radiometer and the one from the infrared camera, data being acquired at the same time. This offset obviously depends on the area of interest selected in the thermal image for further investigation. The farther the area from the front of the vehicle, the greater the offset. In the configuration chosen for the data acquisition, the distance offset was of $12 \mathrm{~m}$. So as to properly compare data from the infrared radiometer and the camera, the temperature measured by the camera for a given distance $d$ will correspond to the one given by the radiometer for the distance $d+12 \mathrm{~m}$.

Thermal images obtained with the camera were analyzed with ThermaCam Researcher 2.9. Several regions of interest (ROI) were defined on the mirror, on the Nextel coating, and on the road pavement. This last one was such that no thermal interference due to circulating vehicles was included in the region of interest. A sketch of the instruments configuration along with an infrared image is given in Figure 2. This value is the distance between the point where the radiometer is making a measurement and the middle of the pavement ROI.

2.3. Data Acquisition. Data acquisition for atmospheric parameters is performed every $3 \mathrm{~m}$ with a speed of $70 \mathrm{~km} / \mathrm{h}$ using a software interface developed under LabVIEW. Pavement emissivity was first supposed to be equal to one and to behave as a black body. A set of road events are collected by the operator (presence of bridges, urban areas, woods on road sides, etc.) that might help in the analysis of road thermal response.

A software interface for data acquisition, also developed under LabVIEW using a specific FLIR SDK toolkit, was made. The code was written to proceed in a snapshot mode for thermal images acquisition. To cope with the camera time integration and limit data transfer, thermal images were only acquired every $12 \mathrm{~m}$, whatever the speed of the vehicle, the speed staying below $70 \mathrm{~km} / \mathrm{h}$ depending on limits due to traffic and using FLIR native format. This corresponds to a variable time frequency, its maximum being $1.6 \mathrm{~Hz}$, and ease the data treatment because of dense traffic flow. Despite the snapshot function, the microbolometer matrix and the whole electronic part of the infrared camera have an integration time of a few milliseconds. This time caused a slight blur in the thermal images when the vehicle is moving (trace behind object over a few pixels). This aspect is compensated by a choice of ROI whose size exceeds the blur effect. All the atmospheric parameters measured by the different sensors such as air temperature and relative humidity were used as input parameters for the infrared camera when recording thermal images. The software interface is given in Figure 3.

2.4. Road Network Pavement. The road network chosen for the test was almost $30 \mathrm{~km}$ long. It included several configurations, from single lane road to multiple lanes highway, passing above and below bridges, with and without trees on the roadside. Measurements were run without sun radiation to avoid artefacts, with a light cloud cover. The vehicle remained in the right lane when the driving was done on highway. A large distance with the vehicle right before was maintained to avoid its thermal signature.

In such a configuration, there were many variations in the materials that could be used for road pavement manufacturing. Furthermore, due to aging pavement and repairs, a wide variety of situations were met along these $30 \mathrm{~km}$. Therefore, a fixed and constant emissivity value could hardly 


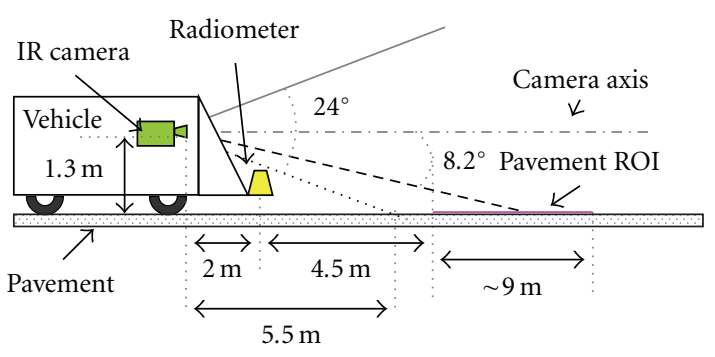

(a)

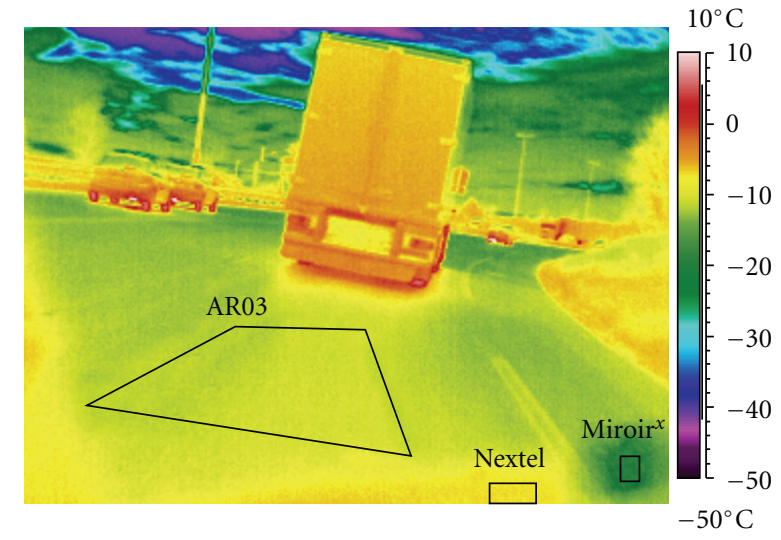

(b)

FIGURE 2: Sketch of instruments configuration (a) and thermal image from the vehicle with ROI (b).

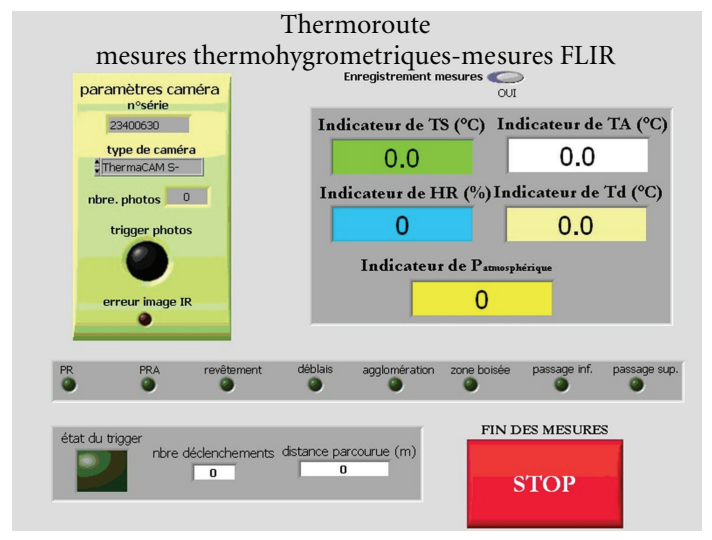

FIGURE 3: Software interface for data acquisition with atmospheric and infrared parameters.

be defined. The pavement emissivity could be considered as close to 1 for measurement close to the normal of the surface $[17,19]$. Based on the literature [20-22], the emissivity decreases when the observation angle gets closer to $90^{\circ}$ (with respect to the normal of the analysed surface). Nevertheless, considering the specularity of the pavement materials and the grazing angle, a correction is expected if a large difference is observed between radiometer and infrared camera data.

\section{Results and Discussion}

3.1. Thermal Mapping Improvement with the Infrared Camera. Pavement temperatures obtained with the infrared radiometer along with the ones from the camera were strongly different before any treatment and environment corrections. The camera temperatures were significantly colder. Nevertheless, the pavement temperature profiles were equivalent. Furthermore, in both cases, major elements of the road environment such as bridges were properly detected by both instruments. The thermal amplitude of surface temperature was larger with the camera $\left(11^{\circ} \mathrm{C}\right)$ than it was with the radiometer $\left(6^{\circ} \mathrm{C}\right)$.
The radiance balance of the whole system could be written as

$$
\begin{aligned}
L_{\text {measured }}= & \tau_{\text {atmosphere }} \cdot \varepsilon_{\text {pavement }} \cdot L_{\text {pavement }} \\
& +\tau_{\text {atmosphere }} \cdot\left(1-\varepsilon_{\text {pavement }}\right) \cdot L_{\text {environment }} \\
& +\left(1-\tau_{\text {atmosphere }}\right) \cdot L_{\text {atmosphere }}
\end{aligned}
$$

with $\tau$ being the atmospheric transmission coefficient $[0$ to 1] and $L$ the radiance in $\mathrm{W} \cdot \mathrm{m}^{-2} \cdot \mathrm{sr}^{-1}$ and $\varepsilon$ being the emissivity [ 0 to 1 ].

In the chosen configuration the distance between the road and the infrared camera is around a few tens of meters for the most distant point where a measurement is done. Neither clouds, nor fog were present during the measurements. The atmospheric transmission coefficient $\tau_{\text {atmosphere }}$ was then considered as equal to one. The transmission attenuation due to relative humidity of atmosphere and of its other component could therefore be neglected [21-23].

The radiance from the environment was obtained thanks to the mirror installed in the field of view of the infrared camera. All bodies in the environment of the thermal scene are considered as emitting infrared radiation as blackbodies. Thus, the radiance measured on the diffusive mirror surface allows computing a mean radiant temperature $T_{\text {environment }}$ taking into account the influence of the surrounding environment on the road surface. As described in the previous paragraphs, measurements were done with the camera having a grazing angle with respect to pavement surface. In such a situation, the emissivity is below the conventional 0.95 to 0.98 value for nonmetallic materials in general and asphalt concrete in particular $[17,19]$. An emissivity value of 0.77 was selected, consistent with the literature [22]. Such a choice was made to fulfill the grazing angle situation. It is also based on the assumption that asphalt concrete emissivity did not depend on the asphalt concrete nature. Therefore, infrared flux variations detected by the camera are only due to temperature variations. This assumption is consistent with the fact that the pavements encountered over the whole 


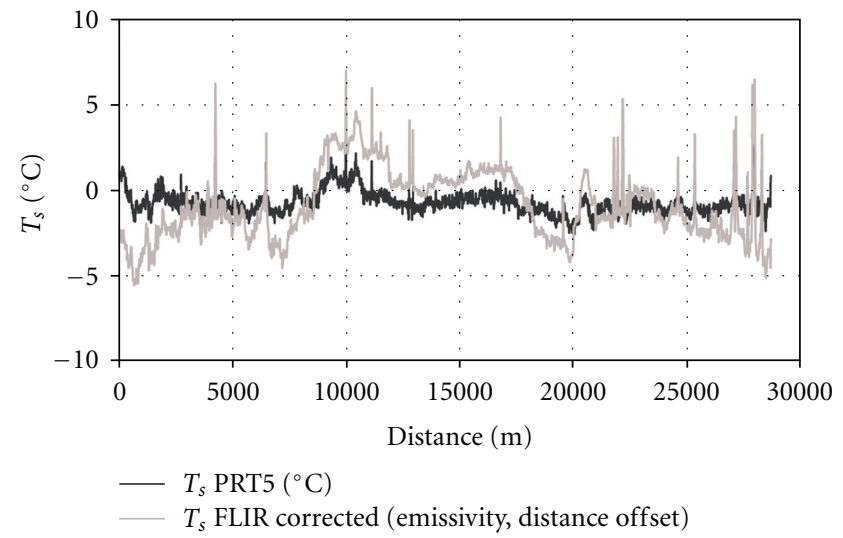

(a)

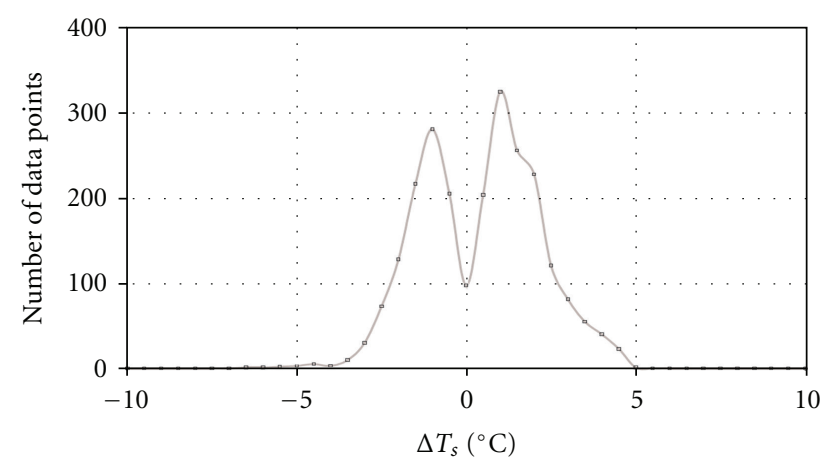

(b)

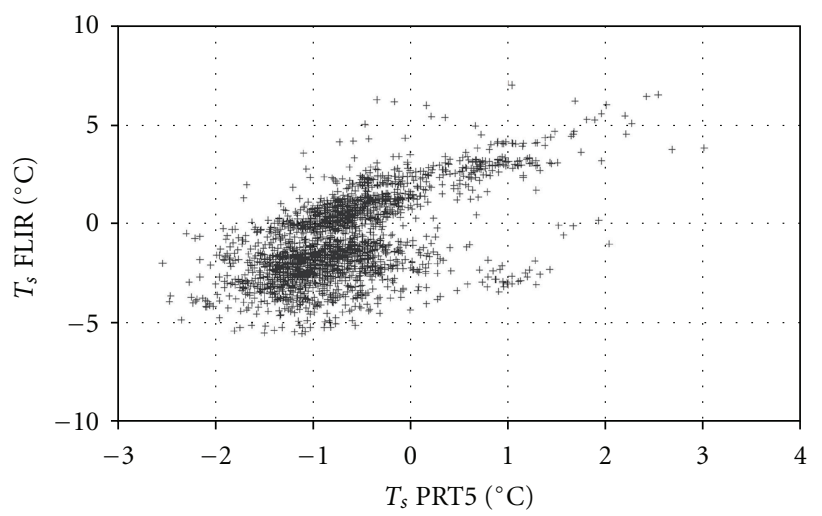

(c)

FIgURE 4: Temperature measurements as a function of distance (emissivity and distance offset corrections completed) (a), pavement temperature difference $\Delta T_{s}$ (b), and surface temperature correlation between the two instruments (c).

itinerary were all aged ones, with close structures. It also allowed getting temperature measurements from the infrared camera matching the values from the PRT5 radiometer chosen as a reference. Thus, pavement temperature with an environment correction could be obtained

$T_{\text {measured }}^{4}=\varepsilon_{\text {pavement }} \cdot T_{\text {pavement }}^{4}+\left(1-\varepsilon_{\text {pavement }}\right) \cdot T_{\text {environment }}^{4} \cdot$
Once the radiative correction completed, a second one was performed to take into account the distance offset, as illustrated in Figure 2 where the measurement with the infrared camera is ahead of the one of the radiometer. Results of the good concordance between the temperatures issued from both instruments once included these corrections are presented in Figure 4(a).

With this set of corrections, the distribution of pavement temperature difference $\Delta T_{s}$ between the two infrared instruments was established. It is represented in Figure 4(b). The distribution is centered above $0^{\circ} \mathrm{C}$, and the average difference was around $0.1^{\circ} \mathrm{C}$, with a standard deviation of $1.8^{\circ} \mathrm{C}$. This distribution reflects the surface temperature measurements, where surface temperature obtained with the infrared camera is either above or below the one given by the radiometer. The data analysis indicated that $T_{s}$ (radiometer) was below $T_{s}$ (FLIR) when the sky view factor was large and close to the half space above the vehicle. In the other cases, the road environment was such that part of the itinerary was partly shaded during daylight either because of the topography or because of the proximity of trees and buildings. Based on the values given in Tables 1 and 2 , data were clearly within the sensitivity and accuracy of the instruments. According to Figure 4(c), there is no clear correlation between surface temperatures obtained from the radiometer and the infrared camera, though two sets of data points could be observed. This absence of clear consistency could be attributed to several factors. First of all the two instruments do not have the same accuracy and the same spectral band. This could induce some discrepancies in the measurements. The second aspect is the emissivity correction with the camera because of the grazing angle. An emissivity distribution over the region of interest, and not only a single value as performed in a first approximation, could improve the matching between the curves of Figure 4(a). This is still based on the assumption that asphalt concrete emissivity was only a function of the observation angle. The last aspect deals with the way the influence of the surrounding environment has been considered. A mirror was installed in the field of view of the camera. But its orientation provided information on the space located behind the camera and the vehicle (see Figure 1). So once the vehicle gets closer and farther of a bridge, the environment correction is not properly taken into account. The environmental correction could therefore be improved, introducing in the FOV of the infrared camera a mirror properly orientated.

3.2. Winter Risk Index, Consistency with Seasons, and Infrastructure Environment. Many possibilities exist in the calculation of the winter risk (WR) of an itinerary. One commonly employed possibility consists in using the average parameters of the itinerary (air temperature $T_{a}$, relative humidity $\mathrm{HR}$, pavement temperature $T_{s}$, and dew point $T_{d}$ ) and analyse how far or close the measurements are from these averages. Indeed, when surface temperature is below the dew point, condensation could occur. And if surface temperature is below $0^{\circ} \mathrm{C}$, some slipperiness might appear, and generating a danger for road users. WR is the sum of two risks, one 
on surface temperature, and a second one on dew point. WR was then defined in this study according to (3), for each data point, giving more weight to the variation of surface temperature. With such definition, a risk exists each time the surface temperature drops below the dew point, with a negative surface temperature. The greater the difference in such configuration, the greater the winter risk WR

$$
\mathrm{WR}=2 \cdot \mathrm{WR}\left(T_{s}\right)+\mathrm{WR}\left(T_{d}\right),
$$

with

$$
\begin{aligned}
& \mathrm{WR}\left(T_{s}\right)= \begin{cases}0, & \text { if }-0.5^{\circ} \mathrm{C} \leq T_{s}-T_{s, \text { average }}<0{ }^{\circ} \mathrm{C}, \\
1, & \text { if }-1^{\circ} \mathrm{C} \leq T_{s}-T_{s, \text { average }}<-0.5^{\circ} \mathrm{C} \ldots,\end{cases} \\
& \mathrm{WR}\left(T_{d}\right)= \begin{cases}0, & \text { if } 0^{\circ} \mathrm{C} \leq T_{d}-T_{d,} \text { average }<0.5^{\circ} \mathrm{C}, \\
1, & \text { if } 0.5^{\circ} \mathrm{C} \leq T_{d}-T_{d,} \text { average }<1^{\circ} \mathrm{C} \ldots\end{cases}
\end{aligned}
$$

Such a method to evaluate the winter risk is not optimum. Indeed, the choice of average values could hide specificities of a given itinerary. Furthermore, if you consider two stretches of a same itinerary, studied at two distinct moments in a same season, such calculation would not allow concatenating the two stretches. The conventional winter risk was then calculated using pavement temperature measurements of the PRT5 radiometer as usually done, and with data from the infrared camera, once the emissivity and distance offset correction done. The global WR shape was respected, though values were clearly different from one instrument to the next. Such difference has to be moderated because of the method chosen for WR calculation. WR is greatly sensitive to the average obtained. In the case of the PRT5 radiometer, the average temperature is slightly above $-0.7^{\circ} \mathrm{C}$, while it is near $-1.3^{\circ} \mathrm{C}$ in the case of the FLIR camera. Average value for dew point is the same in both cases. Therefore, a difference will appear in the conventional WR evaluation.

Measurement with the infrared camera was based on many elements from the road environment, enhancing the thermal amplitude of the ROI. The one used for pavement temperature had a given spatial extent. And due to the grazing angle, pavement points farther from the vehicle appeared colder than the ones near the vehicle. A temperature difference up to $2^{\circ} \mathrm{C}$ was recorded along thermal images based on Figure 2 pavement ROI. This might also contributed to increase the thermal amplitude within the ROI. This could be corrected considering an emissivity distribution within the ROI instead of attributing a constant emissivity. Indeed, emissivity drops quickly when it comes to such low observation angles (below $10^{\circ}$ ). So, once the average pavement temperature was calculated for $\mathrm{WR}$, variations around it were enhanced with the infrared camera and this clearly affected the conventional WR, which appeared greater that the one obtained with the radiometer.

Although this calculation is extremely common, some limits could be easily raised. As illustrated on Figure 4(b), the pavement temperature distributions from both instruments are greatly different though Gaussian in both cases. WR is therefore greatly sensitive to the average temperature obtained. If one itinerary section is studied one day, and a part of this same itinerary section the very same day along with another road stretch, the WR over the common part might not give the same weather risk. Indeed, average values used for the WR risk calculations would be different. Moreover, considering the average parameters of the itinerary could be considered as far-fetched since the temperature balance in any location is the result of its local environment and not of the situation several kilometres before and ahead. The other drawback of such consideration is the consistency of winter risk with seasons and infrastructure environment. The risk should be greater in wintertime than in other seasons, though the condensation risk exists in any season. But using average parameters of the whole itinerary does neither reflect such seasonal modifications, nor the effect of bridges commonly known as colder than the rest of the surface pavement on a road because of a greater convective effect.

To evaluate a more appropriate WR calculation and its consistency with seasons and roads environment, the $30 \mathrm{~km}$ long road stretch described in 2.4 was monitored during a whole year, at least once a month. WR was then calculated considering a moving average of the surface temperature over 250 meters before and after each measurement data point. The average temperature for dew point was unchanged. WR was then defined as

$$
\begin{aligned}
& \mathrm{WR}=2 \cdot \mathrm{WR}\left(T_{s}\right)+\mathrm{WR}\left(T_{d}\right), \\
& \text { with } \\
& \mathrm{WR}\left(T_{s}\right)= \begin{cases}0, & \text { if }-0.5^{\circ} \mathrm{C} \leq T_{s}-T_{s}, \text { moving average }<0{ }^{\circ} \mathrm{C}, \\
1, & \text { if }-1^{\circ} \mathrm{C} \leq T_{s}-T_{s, \text { moving average }}<-0.5^{\circ} \mathrm{C} \ldots,\end{cases} \\
& \mathrm{WR}\left(T_{d}\right)= \begin{cases}0, & \text { if } 0^{\circ} \mathrm{C} \leq T_{d}-T_{d,} \text {, average }<0.5^{\circ} \mathrm{C}, \\
1, & \text { if } 0.5^{\circ} \mathrm{C} \leq T_{d}-T_{d, \text { average }}<1^{\circ} \mathrm{C} \ldots\end{cases}
\end{aligned}
$$

Then comparison of WR established in a conventional way, according to (3), with a WR calculated using moving average for the same data points is presented in Figures 5 (a) and 5(b) in the case of the analysis of data recorded during winter. Then, so as to study the season impact, the WR calculation with a moving average was performed over several months. Figures 5(c) and 5(d) are illustrating this WR during spring and summer months.

A great difference could be noticed between the WR results obtained through the two methods, the conventional one, and with the moving average. In the case of the moving average, the WR amplitude decreases, as spring and then summer get closer. There is always a residual risk since, as indicated before, water condensation over a pavement surface is always possible. The most noticeable point is that the highest values of WR are always obtained at the same locations whatever the season considered for the computation. The other aspect is the consistency of WR established with a moving average with infrastructure environment. Bridges beginnings and ends were plotted in 


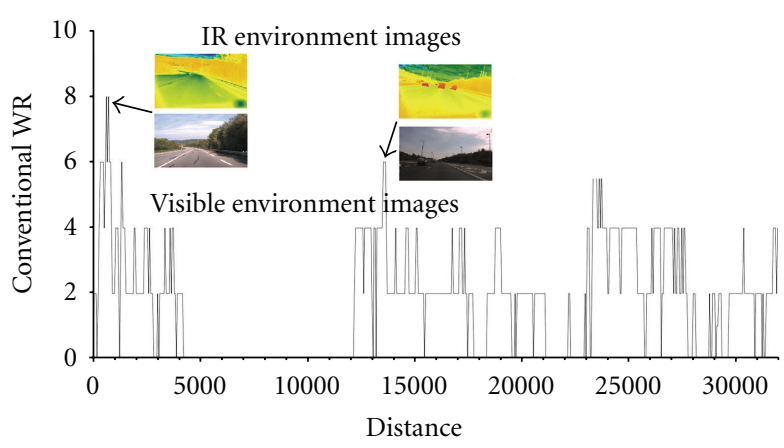

(a) Conventional WR as a function of distance (in m), 2009-01-31

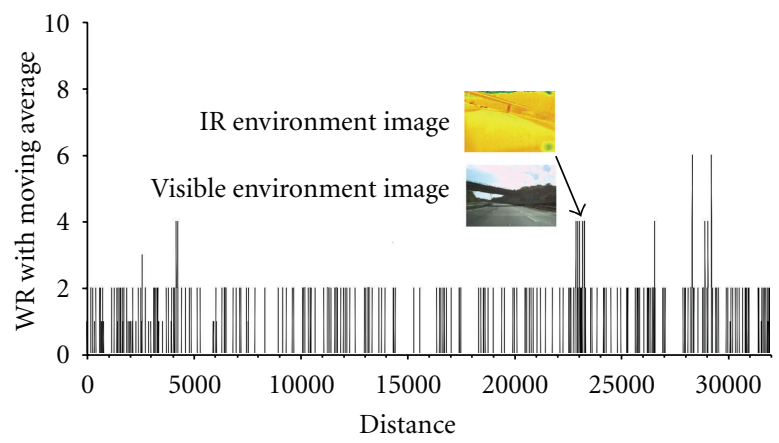

(c) WR as a function of distance (in $\mathrm{m}$ ), using a moving average, 2009-04-02

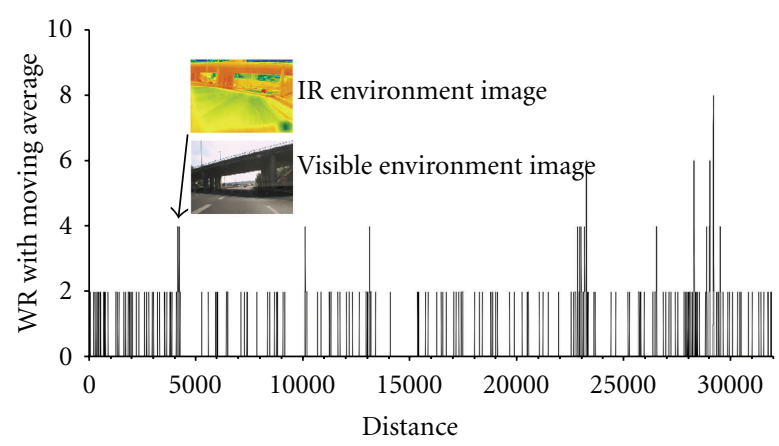

(b) WR as a function of distance (in $\mathrm{m}$ ), using a moving average, 2009-01-31

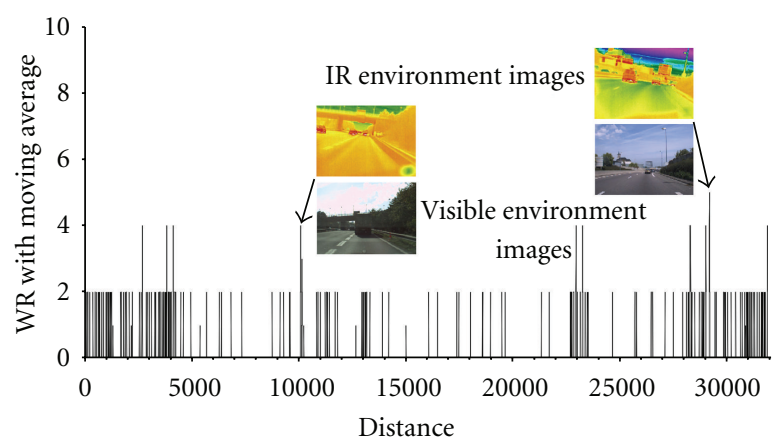

(d) WR as a function of distance (in $\mathrm{m}$ ), using a moving average, 2009-08-19

FIGURE 5: Winter risk indexes of the same road stretch at different seasons; IR and visible images corresponding to road points with highest WR values are provided.

Figure 5. Intense WR is always located on bridges present along the itinerary. Furthermore, woods on roadside are source of large relative humidity. They enhance the water condensation and here again the risk was greater in these locations. These locations were indicated with a risk and could be related to the presence of a forest (high relative humidity), or to the fact that the topography does not allow a large insulation (see Figure 1(b)). In the case of conventional WR, largest values could not be correlated to a specific infrastructure and were obtained in open spaces. Some additional calculations were run using another moving average, with $125 \mathrm{~m}$ before and after each measurement data point. The WR profile obtained was the same as the ones presented in Figure 5, but with different intensities. This could be easily explained by the moving average changes induced in $T_{s}$, average and $T_{d}$, average upon which the WR is based. The choice of the moving average would have to be such that it will properly include specific singularities of the itinerary, without getting a too detailed level that would be useless for road managers.

\section{Conclusion}

The first objective of the work was to establish the possibility to implement an infrared camera on a thermal mapping vehicle. The second one was to study the consistency of a new winter risk calculation with seasons and infrastructure environment. To do so, two instruments were selected. They consisted in a conventional PRT 5 radiometer, and a FLIR S65 camera. A $30 \mathrm{~km}$ long itinerary was chosen, including different road configurations (highways, urban area, bridges, trees, etc.). The infrared camera was installed on the vehicle in such a way that an emissivity correction was necessary, along with a distance offset one, measurements from the camera being ahead the ones obtained from the radiometer. A LabVIEW interface was developed for data acquisition, including atmospheric parameters and infrared images. This road stretch was monitored at least once a month over several months.

Road surface temperatures analysis obtained from the radiometer and the infrared camera have shown great similarities. Comparison was made on an area located between the wheel tracks. Once emissivity and distance correction performed, there was a good agreement between the surface temperature measurements. Data from the infrared camera indicated greater thermal amplitude. This could be explained by the grazing angle that should induce an emissivity correction with a distribution over the region of interest, and not only a single value as performed in a first approximation. The environment correction has also to be optimized to properly take into account the part located ahead of the vehicle and the camera. The winter risk calculation was conducted according to a very traditional and simplistic way. Because of the greater thermal amplitude obtained with the camera, a larger winter risk was deduced along the network with respect to the one obtained with the radiometer. 
A new winter risk calculation, based on the moving average of surface temperature was implemented. This winter risk index has shown a great consistency with respect to infrastructure environment, such as bridge presence and woods on roadside. As spring and summer get closer, the winter risk intensity is reduced. This new index could replace the former one based on the average value of parameters over the whole itinerary. The length of data considered for computing moving average values has however to be defined more precisely. It could be expected that this parameter should depend on the road environment (urban situation or surrounding woods for instance).

As a conclusion, the feasibility of performing thermal mapping with an infrared camera was established. This would improve the performance by measuring pavement temperatures in several lanes at the same time. The position of the camera has to be optimized according to its field of view. Although the thermal images acquisition frequency is comfortable, a reduction would ease data analysis. This could be performed acquiring data from the sole region of interest instead of the whole image, reducing its volume. A compromise has to be found to get information about road surroundings, to avoid radiation from passing vehicles. One major aspect would be to either avoid a grazing observation angle, or to set an emissivity distribution correction over the region of interest. The infrared camera would also ease the implementation of the winter risk index based upon a moving average value of surface temperature, using an appropriate camera field of view that would take into account the appropriate region of interest.

\section{References}

[1] J. E. Thornes, The prediction of ice formation on motorways in Britain, Ph.D. thesis, Department of Geography, University of London, London, UK, 1984.

[2] J. E. Thornes, "Thermal mapping and road-weather information systems for highway engineers," in Highway Meteorology, A. H. Perry and L. J. Symons, Eds., pp. 39-67, Spon Press, London, UK, 1991.

[3] T. Gustavsson and J. Bogren, "Infrared thermography in applied road climatological studies," International Journal of Remote Sensing, vol. 12, no. 9, pp. 1811-1828, 1991.

[4] D. G. Belk, Thermal mapping for a highway gritting network, Ph.D. thesis, University of Sheffield, Sheffield, UK, 1993.

[5] J. Shao, P. J. Lister, and H. B. Pearson, "Thermal Mapping: reliability and repetability," Meteorological Applications, vol. 3, pp. 325-330, 1996.

[6] J. Shao, J. C. Swanson, R. Patterson, P. J. Lister, and A. N. McDonald, "Variation of winter road surface temperature due to topography and application of Thermal Mapping," Meteorological Applications, vol. 4, no. 2, pp. 131-137, 1997.

[7] T. Gustavsson, "Thermal mapping - a technique for road climatological studies," Meteorological Applications, vol. 6, no. 4, pp. 385-394, 1999.

[8] L. Chapman, J. E. Thornes, and A. Bradley, "Modelling of road surface temperature from a geographical parameter database: part 2: numerical," Meteorological Applications, vol. 8, no. 4, pp. 421-436, 2001.
[9] L. Chapman and J. E. Thornes, "A geomatics-based road surface temperature prediction model," Science of the Total Environment, vol. 360, no. 1-3, pp. 68-80, 2006.

[10] L. Chapman and J. E. Thornes, "Small-scale road surface temperature and condition variations across a road profile," in Proceedings of the 14th International Road Weather Conference (SIRWEC '08), Prague, Czech Republic, May 2008.

[11] L. Chapman and J. E. Thornes, "The influence of traffic on road surface temperatures: implications for thermal mapping studies," Meteorological Applications, vol. 12, no. 4, pp. 371380, 2005.

[12] L. Chapman and J. E. Thornes, "A geomatics-based road surface temperature prediction model," Science of the Total Environment, vol. 360, no. 1-3, pp. 68-80, 2006.

[13] J. Bogren, T. Gustavsson, and S. Lindqvist, "A description of a local climatological model used to predict temperature variations along stretches of road," Meteorological Magazine, vol. 121, no. 1440, pp. 157-164, 1992.

[14] J. Norrman, "Slipperiness on roads-an expert system classification," Meteorological Applications, vol. 7, no. 1, pp. 27-36, 2000.

[15] D. Bouris, T. Theodosiou, K. Rados, M. Makrogianni, K. Koutsoukos, and A. Goulas, "Thermographic measurement and numerical weather forecast along a highway road surface," Meteorological Applications, vol. 17, no. 4, pp. 474-484, 2010.

[16] http://www.forumgraphic.eu/prod/index.php/Mesure/sonde -basse-couche.html.

[17] L. Ibos, M. Marchetti, A. Boudenne, S. Datcu, Y. Candau, and J. Livet, "Infrared emissivity measurement device: principle and applications," Measurement Science and Technology, vol. 17, no. 11, pp. 2950-2956, 2006.

[18] S. Datcu, L. Ibos, Y. Candau, and S. Matteï, "Improvement of building wall surface temperature measurements by infrared thermography," Infrared Physics and Technology, vol. 46, no. 6, pp. 451-467, 2005.

[19] M. Marchetti, L. Ibos, V. Muzet et al., "Emissivity measurements of road materials," Quantitative InfraRed Thermography Journal, vol. 1, no. 1, pp. I.2.1-I.2.7, 2004.

[20] X. P. V. Maldague, Theory and Practice of Infrared Technology for Nondestructive Testing, John Wiley \& sons, New York, NY, USA, 2001.

[21] G. Gaussorgues, "La thermographie infrarouge," Techniques et Documentation (France), pp. 386, 1981.

[22] Handbook of Military Infrared Technology, Office of Naval Research Department of the Navy, Washington, DC, USA, 1965.

[23] J. Dumoulin, V. Boucher, and F. Greffier, "Numerical and experimental evaluation of road infrastructure perception in fog and/or night conditions using infrared and photometric vision systems," in Infrared Spaceborne Remote Sensing and Instrumentation XVII, vol. 7453 of Proceedings of SPIE, San Diego, Calif, USA, August 2009. 

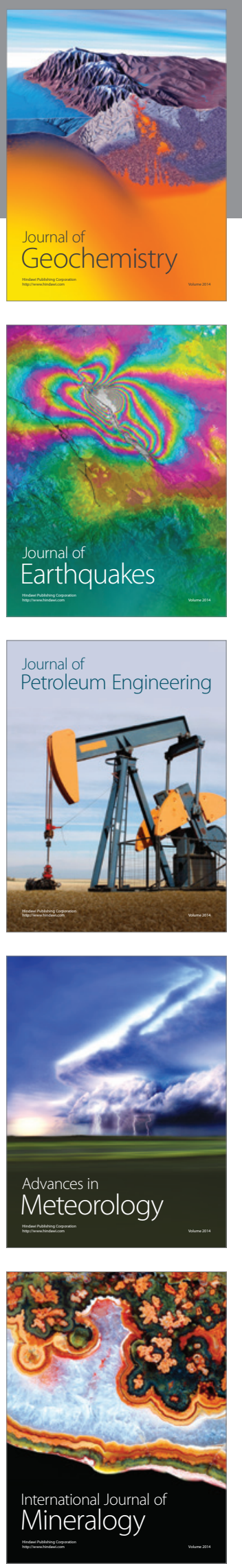
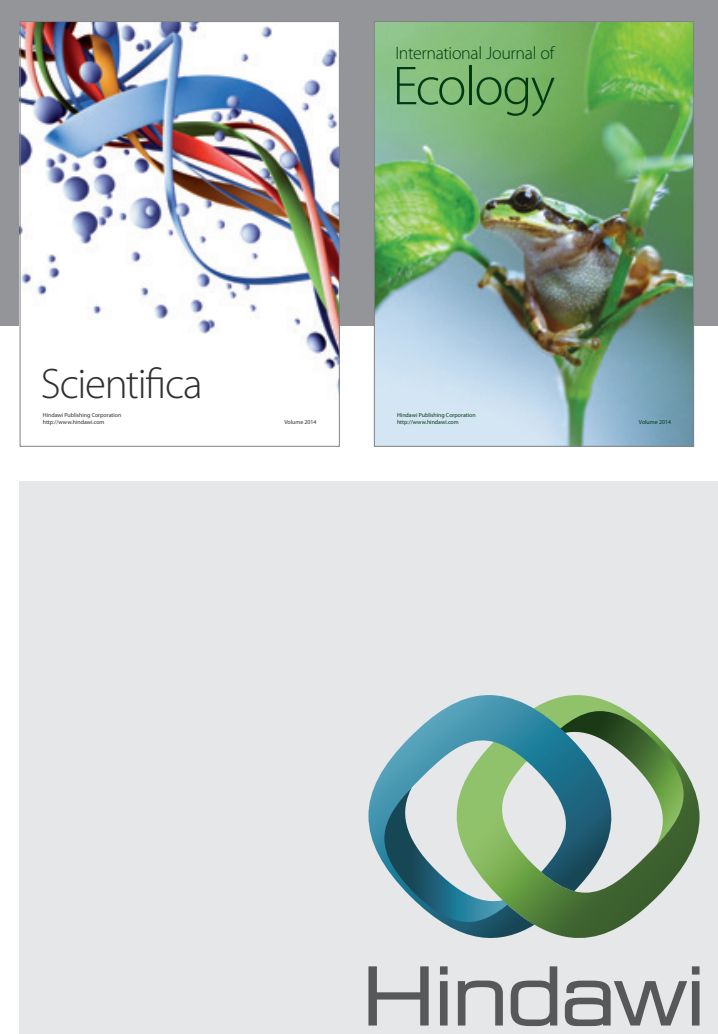

Submit your manuscripts at http://www.hindawi.com
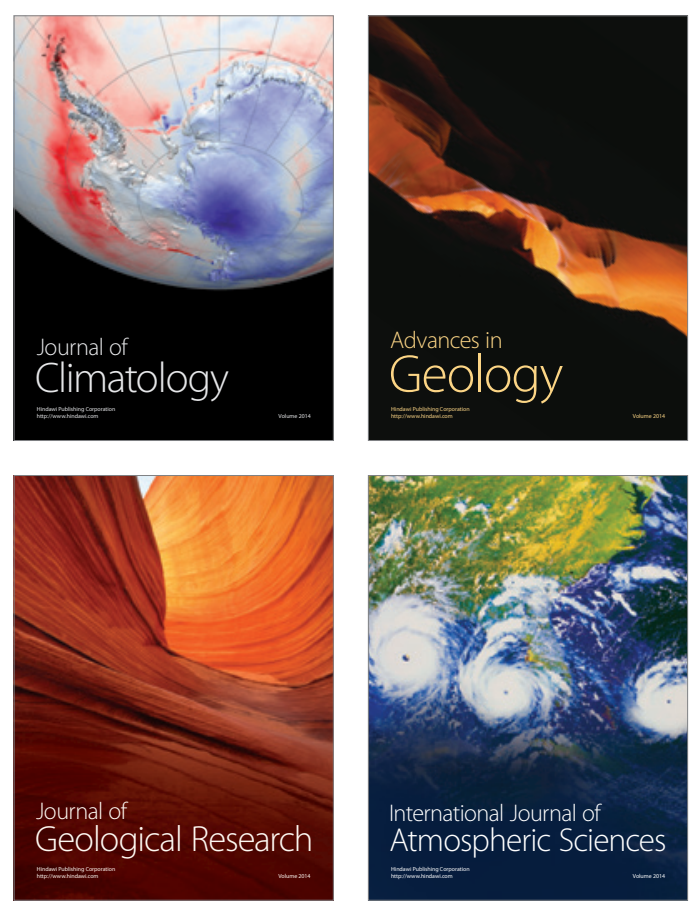
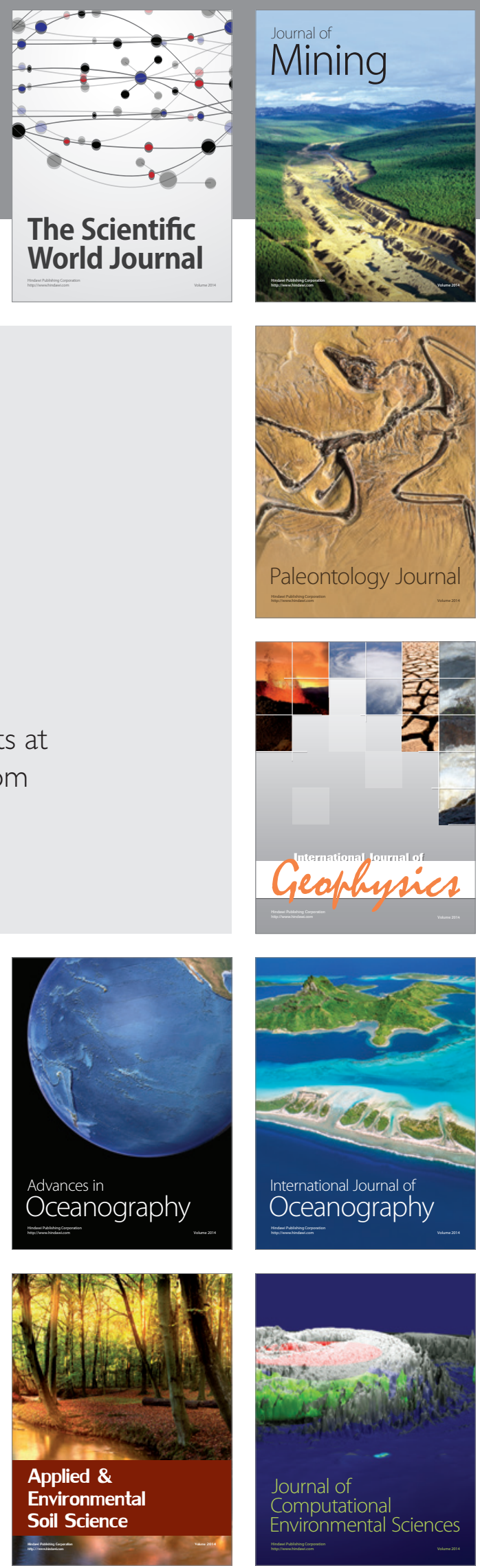